\title{
Is thioredoxin reductase involved in the defense against DNA fragmentation in varicocele?
}

\author{
Gül Özdemirler Erata ${ }^{1}$, Canan Küçükgergin ${ }^{1}$, Gülsan Aktan ${ }^{2}$, Ates Kadioglu ${ }^{2}$, Müjdat Uysal ${ }^{1}$ \\ and Necla Koçak-Toker ${ }^{1}$
}

We aimed to investigate the role of thioredoxin reductase (TR) and inducible heat shock protein 70 (iHsp70) and their relationship with sperm quality in varicocele (VAR) patients. Semen samples were obtained from 16 subfertile men diagnosed as VAR and 10 fertile men who applied to the Andrology Laboratory of Istanbul Medical Faculty of Istanbul University. The sperm TR and iHsp 70 expression levels were determined using Western blot analysis. The TR activity of the sperm was assayed spectrophometrically. The sperm quality was evaluated both by conventional sperm analysis and by a terminal deoxynucleotidyl transferase-mediated dUTP nick end-labeling (TUNEL) technique that assayed DNA-fragmented spermatozoa in semen samples. The percentage of TUNEL-positive spermatozoa in the VAR group $(16.3 \% \pm 5.6 \%)$ was higher than that in the fertile group $(5.5 \% \pm 1.9 \%)$. Significant inverse correlations were detected between the percentage of TUNEL-positive cells and both the concentration $(r=-0.609 ; P=0.001)$ and motility $(r=-0.550$;

$P=0.004)$ of spermatozoa. Both the TR expression and activity were increased significantly in the VAR group $(U=22.0 ; P=0.001$ and $U=33.5 ; P=0.012$, respectively) as analyzed using the Mann-Whitney $U$ Wilcoxon rank sum $W$ test. Furthermore, significant positive correlations were found between TR expression and activity $(r=0.406 ; P=0.040)$ and between TR expression and the percentage of TUNEL-positive cells $(r=0.665 ; P=0.001)$. Sperm iHsp70 expression did not differ between the VAR and fertile groups. In conclusion, increased sperm TR expression might be a defense mechanism against apoptosis in the spermatozoa of men with VAR. Asian Journal of Andrology (2013) 15, 518-522; doi:10.1038/aja.2013.9; published online 22 April 2013

Keywords: DNA damage; inducible heat shock protein 70 (iHsp70); thioredoxin reductase (TR); spermatozoa; varicocele

\section{INTRODUCTION}

Reproduction is a basic process that living organisms need to produce progeny and to evolve by transmitting their genes. However, both the reproductive system and spermatozoa are continuously exposed to reactive oxygen species (ROS) due to the highly active metabolic process occurring during spermatogenesis. Although basal levels of ROS are required for normal sperm functions, the overproduction of ROS leads to lipid peroxidation in the spermatozoa membrane, which in turn can reduce sperm motility and viability and increase sperm DNA damage resulting in infertility. ${ }^{1-6}$

Human spermatozoa have evolved several mechanisms to defend against oxidative stress and minimize the damage caused by ROS. One mechanism is the thioredoxin system which is composed of thioredoxin, thioredoxin reductase (TR) and thioredoxin peroxidase. Thioredoxins are small proteins $(12 \mathrm{kDa})$ that function in maintaining the redox state of oxidized proteins via the reversible oxidation of the cysteine residues in their conserved active site Trp-Cys-Gly-Pro-Cys. ${ }^{7-11}$ In addition, several thioredoxin proteins, specifically Trx-1, Trx-2, TXL-1, ERDJ-5, TXL-1/TRP32 and sperm-specific thioredoxins, namely SPtrx-1, SPtrx-2 and Sptrx-3, have been recently reported. ${ }^{12-17}$ Because these proteins are abundant in spermatogenic cells, attention has been paid to the relationship between infertility and the thioredoxin system.
However, such a relationship has not been clearly reported in the literature.

In contrast, heat shock protein 70 (Hsp70) plays a protective role in the cell, enabling the cell to withstand the negative effects of hyperthermia and other stress conditions by assisting protein folding, transportation and complex formation. They are also produced constitutively under normal conditions. ${ }^{18-20}$ HspA2, which is a sperm-specific constitutive Hsp70, has been reported to assist in the transportation of proteins, the repair of fragmented DNA and the removal of cytoplasm during sperm maturation. ${ }^{21-23}$ Therefore, Hsp70 has been proposed to be involved in the pathogenesis of male infertility. However, there are few studies investigating the association of sperm Hsp70 (both stress-inducible and constitutive) with male factor infertility in the literature. ${ }^{24}$

It has been suggested that varicocele (VAR) is associated with male infertility, but the pathophysiology remains unclear. ${ }^{25-28}$ Several mechanisms have been proposed to explain the causes by which VAR impairs male fertility. Changes in testicular blood flow and venous pressure, Leydig cell dysfunction, oxidative stress and hyperthermia are some of the main suggested mechanisms. ${ }^{27,29}$ In addition, some studies have reported that increased apoptosis has been associated with VAR. ${ }^{25,26,30,31}$ However, for the initiation of apoptosis,

${ }^{1}$ Department of Biochemistry, Istanbul Medical Faculty, University of Istanbul, Çapa, 34093, Istanbul, Turkey and ${ }^{2}$ Department of Urology, Istanbul Medical Faculty, University of Istanbul, Çapa, 34093, Istanbul, Turkey 
several physiological stimuli are required. One of these stimuli is elevated temperature of the testes. Spermatogenesis is well known to be worsened at elevated testis temperatures, implicating the high sensitivity of spermatogenetic cells to heat stress. Thus, heat stress has been observed to suppress sperm maturation subsequently decreasing sperm quality and resulting in infertility. ${ }^{32,33}$ In light of this information, the objective of this study was to investigate the changes in sperm $\mathrm{TR}$ and in the inducible form of Hsp70 (iHsp70) in a group of men with VAR and the effects of these changes on sperm quality.

\section{MATERIALS AND METHODS}

All chemicals were purchased from Sigma-Aldrich (St Louis, MO, USA)

\section{Subjects, semen collection and quality evaluation}

Semen samples were obtained from men who applied to the Andrology Laboratory of Istanbul Medical Faculty of Istanbul University after $72 \mathrm{~h}$ of sexual abstinence. The experimental procedure used in this study met the guidelines of the Ethical Committee of Istanbul University. After liquefaction for 15-30 min at room temperature, the semen samples were analyzed for sperm concentration and motility using a Neubauer hemocytometer superior (Marienfeld, Germany). The results were evaluated according to the guidelines of the WHO (World Health Organization). ${ }^{34}$ Ten fertile donors were used as the control group (mean age: $31.8 \pm 4.2$ years). In the VAR group, 16 males diagnosed as being VAR were included (mean age: $35.0 \pm 5.1$ years). Four of the patients were classified as grade 1 , six as grade 2 and six as grade 3 .

Seminal leukocytes were considered to be normal at concentrations of $\leqslant 1 \times 10^{6}$ peroxidase-positive leukocytes per $\mathrm{ml}$ of semen.

\section{Sperm extraction}

After liquefaction, fresh semen was washed in 10 volumes of ice cold $0.15 \mathrm{moll}^{-1} \mathrm{NaCl}$ and $30 \mathrm{mmol}^{-1}$ imidazole, $\mathrm{pH} 7.0$, and centrifuged at $5000 \mathrm{~g}$ for $20 \mathrm{~min}$. The resulting pellet was lysed in ice cold solution of $30 \mathrm{mmol}^{-1}$ imidazole $\mathrm{pH}$ 7.0, $5 \mathrm{mmol}^{-1}$ DL-dithiothreitol, $0.1 \%$ Triton X-100 and $10 \%$ glycerol. The lysate was cleared by centrifugation at $5000 \mathrm{~g}$ for $20 \mathrm{~min}$. After removing the insoluble material, the supernatant was stored at $-70{ }^{\circ} \mathrm{C}$ until used for the detection of iHsp70 expression. ${ }^{21}$

\section{Swim-up}

The direct swim-up technique was performed without centrifugation. The semen portion was layered gently under the Pure-Sperm Wash solution (Nidacon International AB, Gothenburg, Sweden) and incubated for $1 \mathrm{~h}$ at $37{ }^{\circ} \mathrm{C}$ in a $5 \% \mathrm{CO}_{2}$ incubator (Thermo Electron Corporation Steri-Cult, San Jose, CA, USA). The swim-up portion was then fixed in $1 \%$ paraformaldehyde and used for the terminal deoxynucleotidyl transferase-mediated dUTP nick end-labeling (TUNEL) assay, as described below.

\section{TR activity}

The sperm TR activity was determined using the method of Holmgren and Björnstedt. ${ }^{35}$ In this method, TR catalyses the redox reaction between 5,5'-dithio-bis-2-nitrobenzoic acid and nicotinamide adenine dinucleotide phosphate. At the end of this reaction, 5,5'dithio-bis-2-nitrobenzoic acid is converted to a yellow product, 5-thio-2-nitrobenzoic acid. The decrease in the 5-thio-2-nitrobenzoic acid formation was monitored kinetically at $412 \mathrm{~nm}$. The results were calculated using the extinction coefficient of $13600 \mathrm{~mol}^{-1} \mathrm{~cm}^{-1}$ for 5-thio-2-nitrobenzoic acid and are expressed as mU per mg of sperm protein.

\section{TR and iHsp70 determination by Western blot analysis}

SDS polyacrylamide gel electrophoresis was performed using Bio Rad's mini gel system according to Laemmli's method. ${ }^{36}$ The sperm samples containing $20 \mu \mathrm{g}$ protein per lane were electrophoresed on a $7.5 \%$ gel in Tris-glycine buffer. After electrophoresis, the separated proteins were transferred onto an Immobilon-PVDF membrane (Millipore, Merck, MA, USA), at $20 \mathrm{~V}$ for $2 \mathrm{~h} 15 \mathrm{~min} .{ }^{37}$ The proteins on the membrane were blocked with $3 \%$ low-fat dried milk. After washing in phosphate-buffered saline (PBS) containing 1\% Tween 20 three times, the blots were treated with a $1: 1000$ dilution of monoclonal primer antibodies that recognize iHsp70 (MAB3846; Chemicon International, Temecula, CA, USA) and TR (SC-28321, Santa Cruz Biotechnology Inc., Santa Cruz, CA, USA) and then washed three times with PBS containing $0.1 \%$ Tween 20 . The resulting immunocomplexes were exposed to $1: 10000$ horseradish peroxidaseconjugated goat antimouse IgG (SAB-100; Stressgen Bioreagents Corporation, MI, USA) for $30 \mathrm{~min}$. After washing with PBS containing $0.1 \%$ Tween 20 , the labeled-antigen bands were visualized with an ECL Western blotting detection reagent (Amersham Pharmacia Biotech., Buckinghamshire, UK). The intensity of the bands was semiquantified densitometrically using the Vilber Lourmat gel documentation system and Bio-1D V.97 software, an image analysis program (Vilber Lourmat, Biotechnology Division, Torcy, France). The blots were stripped and subsequently reprobed with an $\alpha$-tubulin monoclonal antibody (CBL270; Chemicon International, Temecula, CA, USA) as an internal standard. The band intensities were normalized to the $\alpha$-tubulin content of individual samples. The value of a fertile donor which was run in the first lane in each assay as a control, was taken as 100 and compared with the other samples. The results were arbitrarily expressed as the percentage of the control value (\%).

The protein content of the sperm samples was measured using bicinchoninic acid. ${ }^{38}$ In this method, the peptide bonds reduce $\mathrm{Cu}^{2+}$ ions from the copper solution to $\mathrm{Cu}^{+}$. The amount of reduced $\mathrm{Cu}^{2+}$ is proportional to the amount of protein present in the solution. The purple-colored product formed by the chelation of bicinchoninic acid with the $\mathrm{Cu}^{+}$ions was spectrophotometrically measured at $562 \mathrm{~nm}$.

\section{TUNEL assay}

The DNA damage was identified using the TUNEL assay. ${ }^{39}$ An in situ cell death detection kit (ApopTag Plus Fluorescein; Chemicon International, Temecula, CA, USA) was used to detect DNA fragmented spermatozoa according to the manufacturer's recommended protocol. Briefly, 3-4 h after the swim-up preparation, approximately $2 \times 10^{6}$ sperm were fixed with $1 \%$ paraformaldehyde for $10 \mathrm{~min}$ at room temperature. Following the fixation, the sample was permeabilized with ethanol/acetic acid. After washing with PBS and equilibration buffer, the TdT-labeled nucleotide mix was added to the slides, which were incubated at $37^{\circ} \mathrm{C}$ for $1 \mathrm{~h}$. After the incubation, the slides were washed with PBS, and an anti-digoxigenin fluorescent antibody was applied the samples, followed by incubation for $30 \mathrm{~min}$ at room temperature. After the antibody exposure, the slides were washed four times with PBS and analyzed under an Olympus fluorescence microscope (Ushio Inc., Tokyo, Japan). As a positive control, one sample was pre-treated with $0.1 \mathrm{U}$ DNase I (Roche Diagnostics, Manheim, Germany) for $30 \mathrm{~min}$ at room temperature. As a negative control, the enzyme terminal transferase was omitted from the reaction mixture. 
Table 1 The semen characteristics and sperm DNA fragmentation (TUNEL) of the fertile controls and VAR patients

\begin{tabular}{|c|c|c|c|c|}
\hline & Fertile controls $(\mathrm{n}=10)($ mean \pm s.d. $)($ median $)$ & $\operatorname{VAR}(\mathrm{n}=16)($ mean \pm s.d. $)($ median $)$ & & istics \\
\hline Sperm concentration $\left(\times 10^{6} \mathrm{ml}^{-1}\right)$ & $53.8 \pm 11.7(55.5)$ & $19.7 \pm 8.6(17.0)$ & $r=-0.609^{b}$ & $P=0.001$ \\
\hline Sperm motility $(\%)(A+B)^{a}$ & $59.9 \pm 3.4(60.5)$ & $31.7 \pm 7.8(31.5)$ & $r=-0.550^{b}$ & $P=0.004$ \\
\hline Morphology by WHO (\%) & $45.4 \pm 9.3(45.0)$ & $32.9 \pm 11.0(33.5)$ & $r=-0.386^{b}$ & $P=0.052$ \\
\hline
\end{tabular}

Abbreviations: TUNEL, terminal deoxynucleotidyl transferase-mediated dUTP nick end-labeling; VAR, varicocele.

${ }^{\mathrm{a}} \mathrm{A}+\mathrm{B}$ : progressive motile sperm.

b Pearson's method was used for correlation analyses.

${ }^{c}$ Statistical analyses were performed using the Mann-Whitney $U$ test. $P<0.05$ compared with the fertile controls (mean \pm s.d.).

Evaluations of DNA-damaged spermatozoa were performed by one investigator using unidentified (blinded) sperm preparations. First, the number of spermatozoa was counted by light microscope. Then, the number of damaged spermatozoa with green fluorescence was expressed as a percentage of the total spermatozoa. At least 200 cells were counted per field, and seven or eight random fields were used to determine the percentage.

\section{Statistical analysis}

The Statistical Package for the Social Sciences (SPSS Inc, Chicago, IL, USA) program was used for the statistical analyses. The data are expressed as the means \pm s.d. The statistical analyses were performed using the Mann-Whitney $U$ Wilcoxon rank sum $W$ test. The correlation coefficients were determined by Pearson's method.

\section{RESULTS}

The semen characteristics of the fertile and VAR groups are given in Table 1.

In our study with a relatively small number of VAR patients, the percentage of DNA-damaged spermatozoa as assayed by the TUNEL technique was higher in the VAR group $(16.3 \% \pm 5.6 \%)$ compared with that of the fertile group $(5.5 \% \pm 1.9 \%)$ (Table 1$)$. In addition, significant inverse correlations were detected between the percentage of TUNEL-positive cells and both the concentration $(r=-0.609$; $P=0.001)$ and motility $(r=-0.550 ; P=0.004)$ of the spermatozoa.

For the Western blot analysis, the band intensities of TR and Hsp70 were normalized to $\alpha$-tubulin as an internal standard. The values were expressed arbitrarily by comparison with one fertile sample (as a control) that was run in the first lane for each assay performed. A significant increase was found in the sperm TR expression in the VAR group compared with the fertile group (Mann-Whitney $U=22.0$; $P=0.001$ ) (Table 2 and Figure 1 ). The sperm TR activity also increased significantly in the VAR group (Table 2) compared with the fertile group (Mann-Whitney $U=33.5 ; P=0.012$ ). Furthermore, a positive correlation was detected between the TR activity and TR expression in the spermatozoa $(r=0.406 ; P=0.040)$ (Figure 2$)$. In addition, we found a significant positive correlation between the percentage of TUNEL-positive cells and the TR expression in spermatozoa ( $r=0.665 ; P=0.001$ ) (Figure 3).

In contrast, the iHsp70 expression in the sperm of the VAR patients did not differ from that in the fertile men (Table 2 and Figure 1). Examples of TUNEL microphotographs from the fertile and VAR groups are shown in Figure 4.

\section{DISCUSSION}

Oxidative damage is considered to be one of the underlying mechanisms in the pathogenesis of male infertility. In fact, there are many reports describing reduced motility, abnormal morphology and decreased capacitation; implicating impaired sperm function due to oxidative damage. ${ }^{40-44}$ In our previous studies, we have shown reduced sperm motility caused by treatment with peroxynitrite, which is a strong oxidizing and nitrating agent. ${ }^{42,43}$ Increased oxidative stress parameters and decreased antioxidant capacity in patients with VAR have also been reported. ${ }^{27,45-47}$ It has been suggested that the impact of oxidative stress on male infertility occurs through a change in the proliferation rate, induction of apoptosis or necrosis, modulation of gene expression and/or stimulation or inhibition of some cell signaling components. ${ }^{5,48-50}$

To the best of our knowledge, there are no studies investigating the thioredoxin system in VAR in the literature. Current studies on sperm-specific thioredoxins show that an association may exist between infertility and the SPtrxs which have functions related to spermatogenesis. ${ }^{12-17}$ In this study, we found that both the expression and activity of TR were significantly increased in the VAR group compared with those in fertile men. The TR expression is thought to be increased as a consequence of a defense against the oxidative and/or apoptotic damage of spermatozoa and the repair of damaged proteins due to oxidative stress. In addition, the elevation of TR expression might have caused the increases in TR activity.

In addition, studies on the association of Hsp70 with infertility are limited in the literature and the reported results are not consistent. Related studies have mainly dealt with constitutive Hsp70 (Hsp70-2) and/or with iHsp70 in experimental animals, ${ }^{33,51-55}$ as well as with HspA2, which is a human analogue of Hsp70-2, ${ }^{21-23}$ mostly in the

Table 2 The expressions of TR and iHsp70 and the activity of TR in the spermatozoa of the fertile controls and VAR patients

\begin{tabular}{|c|c|c|c|c|}
\hline & Fertile controls $(\mathrm{n}=10)($ mean \pm s.d. $)$ & $\operatorname{VAR}(\mathrm{n}=16)($ mean \pm s.d. $)$ & & \\
\hline iHsp70 (\%) & $93.5 \pm 28.2$ & $95.4 \pm 51.2$ & $U=76.0$ & $P=0.856$ \\
\hline TR expression (\%) & $114.3 \pm 26.2$ & $173.8 \pm 54.1$ & $U=22.0$ & $P=0.001$ \\
\hline TR activity (mUTR $\mathrm{mg}^{-1}$ protein) & $184.0 \pm 55.8$ & $283.1 \pm 100.4$ & $U=33.5$ & $P=0.012$ \\
\hline
\end{tabular}

Abbreviations: iHsp70, inducible heat shock protein 70; TR, thioredoxin reductase; VAR, varicocele.

a Statistical analyses were performed using the Mann-Whitney $U$ test.

$P<0.05$ compared with the fertile controls (mean \pm s.d.). 


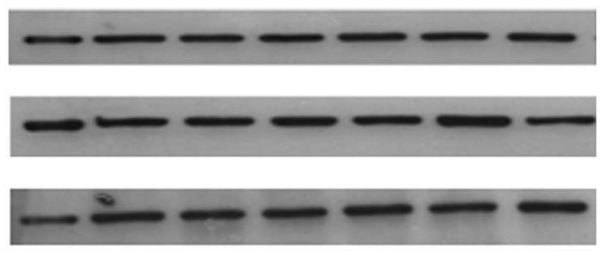

TR

iHSP70

a-tubulin

b

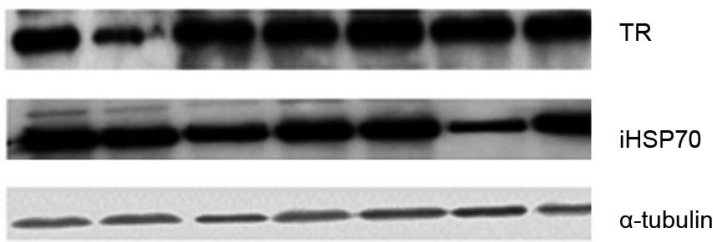

Figure 1 Examples of the expression profiles of TR, iHsp70 and $\alpha$-tubulin of the spermatozoa from the fertile (a) and VAR (b) groups. The band intensities on the Western blots (TR and iHsp70) were normalized to $\alpha$-tubulin as an internal standard. The values were expressed arbitrarily by comparison with a fertile sample (as a control) which was run in the first lane for each assay performed iHsp70, inducible heat shock protein 70; TR, thioredoxin reductase; VAR, varicocele.

testes, spermatids or spermatocyte cultures. However, there are few studies that explore the importance of Hsp70 in human ${ }^{24,27,56,57}$ or animal spermatozoa. ${ }^{58}$ Yesilli et al. ${ }^{27}$ reported that sperm HspA2 activity was lower in infertile men with VAR than in the control group. In addition, sperm HspA2 gene expression was reported to be downregulated in both oligozoospermic patients ${ }^{56}$ and VAR patients. ${ }^{57}$ In contrast, in our previous study, we demonstrated for the first time that Hsp70 was increased in both asthenospermic and oligoasthenospermic infertile men compared with fertile men. ${ }^{24}$ We have assumed that increased $\mathrm{Hsp} 70$ acting as a chaperone prevented protein aggregation and participated in the refolding of damaged proteins following stress. In the present study, we found that iHsp70 remained unchanged in the VAR patients.

The importance of apoptosis or programmed cell death in human spermatozoa is currently a subject of great interest. ${ }^{39,59-61}$ The final stage of programmed cell death is DNA fragmentation. One method to assay fragmented DNA in spermatozoa is the TUNEL technique. Conventional semen parameters are not always sufficient to determine sperm function and male infertility. Therefore, attempts have been made to link some apoptotic alterations, such as DNA fragmentation,

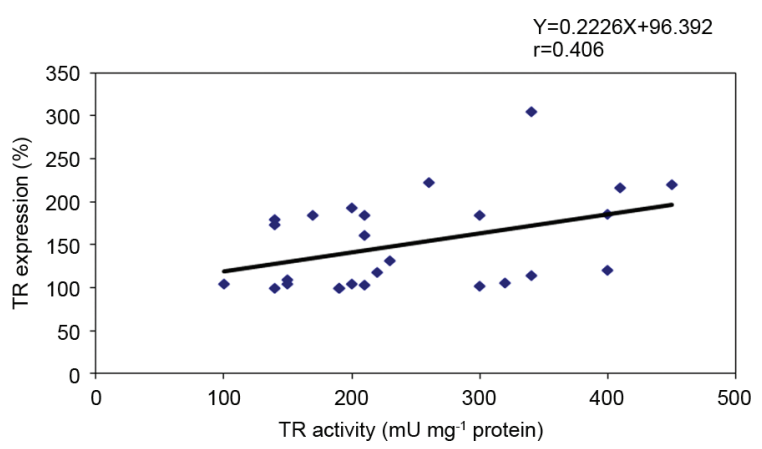

Figure 2 Positive correlation between TR activity and TR expression. TR, thioredoxin reductase.

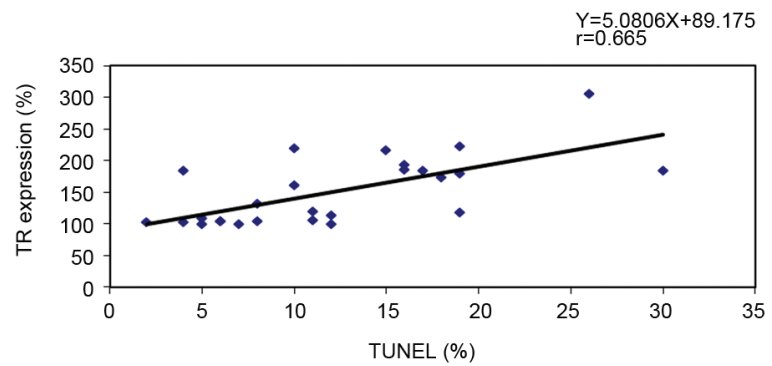

Figure 3 Positive correlation between the TUNEL results and TR expression. TR, thioredoxin reductase; TUNEL, terminal deoxynucleotidyl transferase-mediated dUTP nick end-labeling.

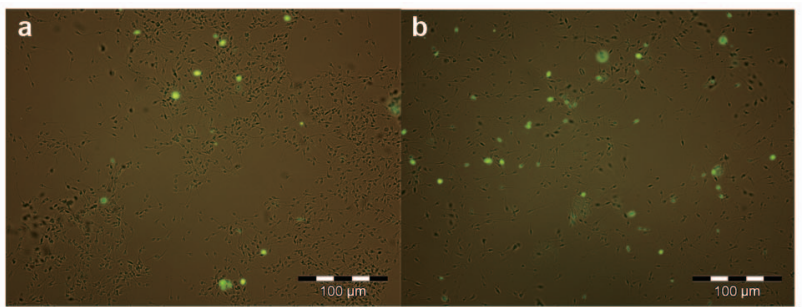

Figure 4 Examples of TUNEL microphotographs from the fertile (a) and VAR (b) groups. TUNEL, terminal deoxynucleotidyl transferase-mediated dUTP nick end labeling; VAR, varicocele.

in the spermatozoa with some conventional semen parameters to evaluate male infertility. ${ }^{39,59,62}$ Indeed, there are a number of studies, including our previous study, ${ }^{24}$ that have proposed the association between the presence of DNA-damaged spermatozoa and poor semen parameters in men. ${ }^{31,48-50,59,61,63}$ In the present study, we found that the levels of DNA-damaged spermatozoa were higher in the VAR group compared with those of the fertile group. Significant inverse correlations between routine semen parameters (such as sperm concentration and motility) and the percentage of DNA-damaged spermatozoa were also observed. This increase in DNA-damaged spermatozoa confirmed the harmful effects of apoptosis on sperm quality.

In sperm exposed to stress, protein refolding and transportation are disrupted, and apoptosis is increased. The occurrence of these events in protein structures may stimulate increases in TR expression and activity. In conclusion, in our study, TR might be increased to assist in the repair of oxidized cell molecules, leading to the regeneration of essential thiol groups that protect proteins from oxidative stress and/ or apoptosis in VAR. However, the limitations of this study include the relatively small overall number of subjects and the potential for unidentified confounding clinical parameters in these patients diagnosed with VAR.

\section{AUTHOR CONTRIBUTIONS}

$\mathrm{CK}$ and GA have done experimental work. AK has supplemented clinical material and MU, NKT, GÖE have spent effort in planning the work, evaluating of the results and writing the paper.

\section{COMPETING FINANCIAL INTERESTS}

All authors declare that there are no competing financial interests. 


\section{ACKNOWLEDGMENTS}

This work was supported by the Research Fund of the University of Istanbul (No. 382/03062005).

1 Fuji J, Yoshihito I, Matsuki S, Ishii T. Cooperative function of antioxidant and redox systems against oxidative stress in male reproductive tissues. Asian J Androl 2003; 5: 231-42.

2 Garrido N, Meseguer M, Simon C, Pellicer A, Remohi J. Pro-oxidative and antioxidative imbalance in human semen and its relation with male fertlity. Asian $\mathrm{J}$ Androl 2004; 6: 59-65.

3 Sikka SC Relative impact of oxidative stress on male reproductive function. Curr Med Chem 2001; 8: 851-62.

4 Pasqualotto FF, Sharma RK, Nelson DR, Thomas AJ, Agarwal A. Relationship between oxidative stress, semen characteristics, and clinical diagnosis in men undergoing infertility investigation. Fertil Steril 2000; 73: 459-64.

5 Taylor CT. Antioxidants and reactive oxygen species in human fertility. Environ Toxicol Pharmacol 2001; 10: 189-98.

6 Moustafa MH, Sharma RK, Thornton J, Mascha E, Abdel-Hafez MA et al. Relationship between ROS production, apoptosis and DNA denaturation in spermatozoa from patients examined for infertility. Hum Reprod 2004; 19: 129-38.

7 Nordberg J, Arner ESJ. Reactive oxygen species, antioxidants, and the mammalian thioredoxin system. Free Rad Biol Med 2001; 31: 1287-312.

8 Jurado J, Prieto-Alamo M, Madrid-Risquez J, Pueyo C. Absolute gene expression patterns of thioredoxin and glutaredoxin redox systems in mouse. $\mathrm{J}$ Biol Chem 2003; 278: 45546-54.

9 Arner ES J, Holmgren A. Physiological functions of thioredoxin and thioredoxin reductase. Eur J Biochem 2000; 267: 6102-9.

10 Nakamura $\mathrm{H}$. Thioredoxin as a key molecule in redox signaling. Antioxid Redox Signal 2004; 6: 15-7.

11 Watson WH, Yang X, Choi YE, Jones DP, Kehrer JP. Thioredoxin and its role in toxicology. Toxicol Sci 2004; 78: 3-14.

12 Miranda-Vizuete A, Ljung J, Damdimopoulos AE, Gustaffson J, Oko R et al. Characterization of Sptrx, a novel member of the thioredoxin family specifically expressed in human spermatazoa. J Biol Chem 2001; 276: 31567-74.

13 Yu Y, Oko R, Miranda-Vizuete A. Developmental expression of spermatid-specific thioredoxin-1 protein. Transient association to the longitudinal columns of the fibrous sheath during sperm tail formation. Biol Reprod 2002; 67: 1546-54.

14 Jimenez A, Oko R, Gustaffson J, Spyrou G, Pelto-Huikko M et al. Cloning, expression and characterization of mouse spermatid specific thioredoxin-1 gene and protein. $\mathrm{Mol}$ Hum Reprod 2002; 8: 710-8.

15 Sadek CM, Damdimopoulos AE, Pelto-Huikko M, Gustaffson J, Spyrou G et al. Sptrx-2, a fusion protein composed of one thioredoxin and three tandemly repeated NDP-kinase domains is expressed in human testis germ cells. Genes Cells 2001; 6: 1077-90.

16 Miranda-Vizuete A, Tsang K, Yu Y, Jimenez A, Pelto-Huikko M et al. Cloning and developmental analysis of murid spermatid-specific thioredoxin-2 (SPTRX-2), a novel sperm fibrous sheat protein and autoantigen. J Biol Chem 2003; 278: 44874-85.

17 Jimenez A, Zu W, Rawe VY, Pelto-Huikko M, Flickinger PS et al. Spermatocyte/ spermatid-specific thioredoxin-3, a novel golgi apparatus-associated thioredoxin, is a spesific marker of abberrant spermatogenesis. J Biol Chem 2004; 279: 34971-82.

18 De Maio A. Heat shock proteins: Facts, thoughts, and dreams. Shock 1999; 11: 1-12.

19 Jaattela M. Heat shock proteins as cellular lifeguards. Ann Med 1999; 31: 261-71.

20 Gullo CA, Teoh G. Heat shock proteins: to present or not, that is the question. Immunol Lett 2004; 94: 1-10.

21 Huszar G, Stone K, Dix D, Vigue L. Putative creatine kinase M-isoform in human sperm is identifies the 70-kilodalton heat shock protein HspA2. Biol Reprod 2000; 63: 925-32.

22 Son WY, Hwang SH, Han CT, Lee JH, Kim S et al. Specific expression of heat shock protein HspA2 in human male germ cells. Mol Hum Reprod 1999; 5: 1122-6.

23 Son WY, Han CT, Hwang SH, Lee JH, Kim S et al. Repression of HspA2 messenger RNA in human testes with abnormal spermatogenesis. Fertil Steril 2000; 73: 1138-44.

24 Erata GO, Toker NK, Durlanık O, Kadıoglu A, Aktan G et al. The role of heat shock protein 70 (Hsp70) in male infertility: Is it a line of defense against sperm DNA fragmentation? Fertil Steril 2008; 90: 322-7.

25 Onur R, Semerciöz A, Orhan I, Yekeler H. The effects of melatonin and the antioxidant defence system on apoptosis regular proteins ( $\mathrm{Bax}$ and $\mathrm{Bcl}-2$ ) in experimentally induced varicocele. Urol Res 2004; 32: 204-8.

26 Saleh RA, Agarwal A, Sharma RK, Said TM, Sika SC et al. Evaluation of nuclear DNA damage in spermatozoa from infertile men with varicocele. Fertil Steril 2003; 80: 1431-6.

27 Yeşilli Ç, Mungan G, Seçkiner İ, Akduman B, Açıkgöz Ș et al. Effect of varicocelectomy on sperm creatine kinase, HspA2 chaperone protein (creatine kinase-M type), LDH, $\mathrm{LDH}-\mathrm{X}$, and lipid peroxidation product levels in infertile men with varicocele. Urology 2005; 66: 610-5.

28 Pasqualotto FF, Agarwal A. Varicocele and male infertility: an evidence based review. Arch Med Sci 2009; 5: S20-7

29 Kısa Ü, Başar MM, Ferhat M, Yılmaz E, Başar H et al. Testicular tissue nitric oxide and thiobarbituric acid reactive substance levels: evaluation with respect to the pathogenesis of varicocele. Urol Res 2004; 32: 196-9.

30 Benoff SH, Millan C, Hurley IR, Napolitano B, Marmar JL. Bilateral increased apoptosis and bilateral accumulation of cadmium in infertile men with left varicocele. Hum Reprod 2004; 19: 616-27.
31 Zini A, Blumenfeld A, Libman J, Willis J. Beneficial effect of microsurgical varicocelectomy on human sperm DNA integrity. Hum Reprod 2005; 20: 1018-21.

32 Allamaneni SSR, Naughton CK, Sharma RK, Thomas AJ, Agarwal A. Increased seminal reactive oxygen species levels in patients with varicocele correlate with varicocele grade but not with testis size. Fertil Steril 2004; 82: 1684-6.

33 Rockett JC, Mapp FL, Garges JB, Luft JC, Mori C et al. Effects of hyperthermia on spermatogenesis, apoptosis, gene expression, and fertility in adult male mice. Biol Reprod. 2001; 65: 229-39.

34 World Health Organization. Laboratory Manual for the Examination and Processing of Human Semen, 5th ed. Cambridge, Cambridge University Press, 2010.

35 Holmgren A, Björnstedt M. Thioredoxin and thioredoxin reductase. Methods Enzymol 1995; 252: 199-209.

36 Laemmli UK. Cleavage of structural proteins during assebly of the head of bacteriophage T4. Nature 1970; 227: 680-5.

37 Towbin H, Stashelin T, Gordon J. Electrophoretic transfer of proteins from polyacrylamide gels to nitrocellulose sheets: procedures and some applications. Proc Natl Acad Sci U S A 1979; 76: 4350-4.

38 Smith PK, Krohn RI, Hermanson GT, Mallia AK, Gartner FH et al. Measurement of protein using bicinchoninic acid. Anal Biochem 1985; 150: 76-85.

39 Shen HM, Dai J, Chia SE, Lim A, Ong CN. Detection of apoptotic alterations in sperm in subfertile patients and their correlations with sperm quality. Hum Reprod 2002; 5: 1266-73.

40 Imai $\mathrm{H}$, Suzuki $\mathrm{K}$, Ishizaka $\mathrm{K}$, Ichinose $\mathrm{S}$, Oshima $\mathrm{H}$ et al. Failure of the expression of phospholipid hydroperoxide glutathione peroxidase in the spermatozoa of human infertile males. Biol Reprod 2001; 64: 674-83.

41 Aitken RJ. Free radicals, lipid peroxidation and sperm function. Reprod Fertil Dev 1995; 7: 659-68.

42 Kocak-Toker N, Aktan G, Aykac-Toker G. The role of Na,K-ATPase in human sperm motility. Int J Androl 2002; 25: 180-5.

43 Öztezcan S, Türkoğlu ÜM, Kervancıoğlu E, Koçak T, Koçak-Toker N et al. In vitro effects of peroxynitrite on human spermatozoa. Andrologia 1999; 31: 195-8.

44 Kefer JC, Agarwal A, Sabanegh E. Role of antioxidants in the treatment of male infertility. Int J Urol 2009; 16: 449-57.

45 Chen SS, Chang LS, Wei YH. Oxidative damage to proteins and decrease of antioxidant capacity in patients with varicocele. Free Radical Biol Med 2001; 30: 1328-34.

46 Abd-Elmoaty MA, Saleh R, Sharma R, Agarwal A. Increased levels of oxidants and reduced antioxidants in semen of infertile men with varicocele. Fertil Steril 2010; 94 : 1531-4

47 Hendin BN, Kolettis PN, Sharma RK, Thomas AJ, Agarwal A. Varicocele is associated with elevated spermatozoal reactive oxygen species production and diminished seminal plasma antioxidant capacity. J Urol 1999; 161: 1831-4.

48 Lopes S, Sun JG, Jurisicova A, Meriano J, Casper RF. Sperm deoxyribonucleic acid fragmentation is increased in poor-quality semen samples and correlates with failed fertilization in intracytoplasmic sperm injection. Fertil Steril 1998; 69: 528-32.

49 Zini A, Bielecki R, Phang D, Zenzes MT. Correlations between two markers of sperm DNA integrity, DNA denaturation and DNA fragmentation, in fertile and infertile men. Fertil Steril 2001; 75: 674-7.

50 Wang X, Sharma RK, Sika SC, Thomas AJJr, Falcone T et al. Oxidative stress is associated with increased apoptosis leading to spermatozoa DNA damage in patients with male factor infertility. Fertil Steril 2003; 80: 531-5.

51 Dix DJ, Allen JW, Collins BW, Poorman-Allen P, Mori C et al. HSP70-2 is required for desynapsis of synaptonemal complexes during meiotic prophase in juvenile and adult mouse spermatocytes. Development 1997; 124: 4595-603.

52 Eddy EM. HSP70-2 heat-shock protein of mouse spermatogenic cells. J Exp Zool 1998; 282: 261-71.

53 Mori C, Nakamura N, Dix DJ, Fujioka M, Nakagawa S et al. Morphological analysis of germ cell apoptosis during postnatal testis development in normal and Hsp70-2 knockout mice. Dev Dyn 1997; 208: 125-36.

54 Sarge KD. Male germ cell-specific alteration in temperature set point of the cellular stress response. J Biol Chem 1995; 270: 18745-8.

55 Saradha B, Vaithinathan S, Mathur PP. Lindane alters the levels of HSP70 and clusterin in adult rat testis. Toxicol 2008; 243: 116-23.

56 Cedenho AP, Lima SB, Cenedeze MA, Spaine DM, Ortiz V et al. Oligozoospermia and heatshock protein expression in ejaculated spermatozoa. Human Rep 2006; 21: 1791-4.

57 Lima SB, Cenedeze MA, Bertoola RP, Filho PAH, Oehninger SO et al. Expression of the HSPA2 gene in ejaculated spermatozoa from adolescents with and without varicocele. Fertil Steril 2006; 86: 1659-63.

58 Huang SY, Kuo YH, Lee YP, Tsou HL, Lin EC et al. Association of heat shock protein 70 with semen quality in boars. Anim Reprod Sci 2000; 63: 231-40.

59 Agarwal A, Said TM. Role of sperm chromatin abnormalities and DNA damage in male infertility. Hum Reprod Update 2003; 9: 331-45.

60 O'Brein J, Zini A. Sperm DNA integrity and male infertility. Urology 2005; 65: 16-22.

61 Sakkas D, Moffatt O, Manicardi GC, Mariethoz E, Tarozzi N et al. Nature of DNA damage in ejaculated human spermatozoa and the possible involvement of apoptosis. Biol Reprod 2002; 66: 1061-7.

62 Oosterhuis GJ, Mulder AB, Kalsbeek-Batenburg E, Lambalk CB, Schoemaker J et al. Measuring apoptosis in human spermatozoa: a biological assay for semen quality. Fertil Steril 2000; 74: 245-50.

63 Sun JG, Jurisicova A, Casper RF. Detection of deoxyribonucleic acid fragmentation in human sperm: correlation with fertilization in vitro. Biol Reprod 1997; 56: 602-7. 